\title{
The cholesteryl ester transfer protein (CETP) gene and the risk of Alzheimer's disease
}

\author{
Alejandro Arias-Vásquez • Aaron Isaacs • \\ Yurii S. Aulchenko • Albert Hofman • Ben A. Oostra • \\ Monique Breteler • Cornelia M. van Duijn
}

Received: 13 February 2007 / Accepted: 17 April 2007 / Published online: 15 May 2007

(C) Springer-Verlag 2007

\begin{abstract}
Like the apolipoprotein E (APOE) gene, the most common genetic determinant for Alzheimer's disease (AD), the cholesteryl ester transfer protein (CETP) is involved in lipid metabolism. We studied the I405V polymorphism of the CETP gene in relation to $\mathrm{AD}$. We genotyped $544 \mathrm{AD}$ cases and 5,404 controls from the Rotterdam study, using a TaqMan allelic discrimination assay. Odds ratios (ORs) for $\mathrm{AD}$ were estimated using logistic regression analysis. CETP VV carriers showed significantly increased high-density lipoprotein levels compared to the IV and II carriers. In the overall analysis of $\mathrm{AD}$, the risk of disease for the $\mathrm{VV}$ carriers of the CETP polymorphism was non-significantly increased compared to II carriers $\mathrm{OR}_{\mathrm{VV}}=1.33,95 \%$ confidence interval (CI) 0.96-1.90 $p=0.08$ ). In those without the APOE*4 allele, the risk of $\mathrm{AD}$ for $\mathrm{VV}$ carriers was increased 1.67 -fold $(95 \% \mathrm{CI}$ $1.11-2.52, p=0.01)$. The difference in the relationship between CETP and $\mathrm{AD}$ between $\mathrm{APOE}^{*} 4$ carriers and APOE*4 non-carriers was statistically significant ( $p$ for interaction $=0.04$ ). Our results suggest that the VV genotype of the I405V polymorphism of the CETP gene increases the
\end{abstract}

A. Arias-Vásquez · A. Isaacs · Y. S. Aulchenko · A. Hofman •

M. Breteler · C. M. van Duijn

Department of Epidemiology \& Biostatistics,

Erasmus Medical Center Rotterdam,

Rotterdam, The Netherlands

B. A. Oostra

Department of Clinical Genetics,

Erasmus Medical Center Rotterdam,

Rotterdam, The Netherlands

A. Arias-Vásquez ( $\square)$

Genetic Epidemiology Unit,

Department of Epidemiology \& Biostatistics,

Erasmus Medical Center Rotterdam,

P.O. Box 2040, 3000 CA Rotterdam, The Netherlands

e-mail: a.ariasvasquez@erasmusmc.nl risk of $\mathrm{AD}$ in the absence of the $\mathrm{APOE}^{*} 4$ allele, probably through a cholesterol metabolism pathway in the brain.

Keywords Alzheimer's disease - Rotterdam study ·

CETP gene $\cdot$ APOE-CETP interaction · Association analysis

\section{Introduction}

Alzheimer's disease (AD) is a complex neurodegenerative disorder characterized by progressive memory loss and deterioration of cognitive function. Of the many genes studied thus far, the only consistently replicated genetic risk factor for $\mathrm{AD}$ has been the apolipoprotein $\mathrm{E}$ (APOE) gene. APOE, which transports cholesterol in the brain [1], may relate to $\mathrm{AD}$ by modifying the production of Amyloid $\beta$ $(A \beta)$. High cellular cholesterol may promote $A \beta$ production and senile plaque deposition, thus increasing the risk of $\mathrm{AD}$ [2-7]. Cholesterol dysregulation is linked to the pathogenesis of $\mathrm{AD}[8,9]$. Lack of cholesterol supply to neurons impairs neurotransmission and synaptic plasticity [10] and induces neurodegeneration and tau pathology [11]. Additionally, there is some evidence that patients treated with cholesterol lowering drugs, such as statins, have a reduced prevalence of $\mathrm{AD}$ [12].

High-density lipoprotein (HDL), essential for the removal of excess cholesterol from cells, exerts several potentially antiatherogenic effects, including reverse cholesterol transport from peripheral cells to the liver [13]. Cholesteryl ester transfer protein (CETP) is a key player in lipid metabolism that catalyses the transfer of cholesteryl esters from HDL particles to triglyceride-rich lipoproteins in exchange for triglycerides [14]. CETP, a protein composed of 439 amino acid residues, is coded by the CETP gene, which is located on chromosome $16 \mathrm{q} 21$ and contains 14 exons. The $405 \mathrm{~V}$ allele of the CETP 
I405V polymorphism (rs5882) in exon 14 was previously associated with lower levels of CETP protein, higher levels of circulating HDL [15], a lower incidence of cardiovascular disease [15], and longer survival [16].

Studies evaluating the role of the CETP gene in AD have shown intriguing results. While one previous study [17] showed evidence that the C-629A polymorphism of the CETP gene modifies the risk of $\mathrm{AD}$ in association with the APOE gene by reducing the risk of $\mathrm{AD}$, another study found no effect of this gene on the disease [18]. We studied the I405V polymorphism of the CETP gene in relation to $\mathrm{AD}$ in a large population-based study and investigated whether this polymorphism is independently associated with $\mathrm{AD}$, or acts in concert with the APOE gene in conferring risk for the disease.

\section{Materials and methods}

\section{Study population}

Our study is part of the Rotterdam study, a populationbased follow-up study of determinants of diseases in the elderly. All inhabitants of Ommoord, a suburb of Rotterdam, aged 55 years or more, were invited to participate. The design of the study was previously described [19]. From all subjects, an informed consent was obtained and the Medical Ethics committee of the Erasmus Medical Center approved the study. A number of 7,983 participants (response rate of 78\%) were examined at baseline (1990 to 1993). Information on age, smoking behavior, and medical history was obtained using a computerized questionnaire.

\section{Patient ascertainment}

Dementia was diagnosed following a three-step protocol [20, 21]. All participants were screened at follow-up visits using two tests of cognition: the mini-mental state examination (MMSE) [22] and the geriatric mental state schedule (GMS) [23]. Participants that were screen-positives (MMSE score $<26$ or GMS organic level $>0$ ) underwent the Cambridge examination for mental disorders of the elderly (CAMDEX). In addition, the cohort was continuously monitored for incident dementia through a computerized link between the study database and the medical records from general prac- titioners and the Regional Institute for Outpatient Mental Health Care until January 1, 2005. The diagnosis of dementia, and dementia subtype, was made in accordance with accepted criteria for dementia (DSM-III-R) [24] and Alzheimer's disease (NINDS-ADRDA) [25] by a panel consisting of a neurologist, a neuropsychologist and a research physician.

\section{Genotyping}

DNA was extracted from whole blood samples using standard methods [26]. The APOE gene was genotyped using the conditions described by Wenham et al. [27]. Samples were genotyped for the CETP I405V polymorphism using a TaqMan allelic discrimination Assay-By-Design (Applied Biosystems, Foster City, CA). We genotyped 317 samples twice and used them as controls by comparing both genotypes, and if present, samples with discordant genotypes were excluded. Forward and reverse primer sequences are available on request. The assays utilized $5 \mathrm{ng}$ of genomic DNA and $2 \mu \mathrm{l}$ reaction volumes. The amplification and extension protocol was as follows: an initial activation step of $10 \mathrm{~min}$ at $95^{\circ} \mathrm{C}$ preceded 40 cycles of denaturation at $95^{\circ} \mathrm{C}$ for $15 \mathrm{~s}$. and annealing and extension at $50^{\circ} \mathrm{C}$ for $60 \mathrm{~s}$. Allele-specific fluorescence was then analyzed on an ABI Prism 7900HT Sequence Detection System with SDS v 2.1 (Applied Biosystems, Foster City, CA).

\section{Statistical analysis}

Genotype frequency of the CETP I405V was compared between cases and controls and Hardy-Weinberg equilibrium (HWE) was assessed for all genotypes using the $\chi^{2}$ test. Odds ratios (OR) and 95\% confidence intervals (CI) were estimated using multivariate logistic regression, adjusting for age, gender, and $\mathrm{APOE}^{*} 4$ status, using all available $\mathrm{AD}$ cases (prevalent and incident). The APOE*4 stratified analyses were adjusted for age and gender. All analyses were performed using SPSS 11.0

\section{Results}

Table 1 shows the general characteristics of the study population. The distribution of the CETP I405V genotypes was
Table 1 General characteristics of the study population stratified by CETP genotype

${ }^{*} p=0.001$

\begin{tabular}{llll}
\hline Genotype & II & IV & VV \\
\hline Total typed (\%) & $2,949(36.9)$ & $2,826(35.4)$ & $646(10.1)$ \\
Mean age of entry in years (SD) & $69.4(9.2)$ & $69.5(9.2)$ & $69.1(9.0)$ \\
Female (\%) & $1,702(59.9)$ & $1,608(59.1)$ & $369(59.0)$ \\
Mean HDL levels mmol/1 (SD)* & $1.33(0.37)$ & $1.34(0.36)$ & $1.39(0.39)$ \\
Mean total cholesterol levels mmol/l (SD) & $6.61(1.21)$ & $6.60(1.24)$ & $6.61(1.23)$ \\
APOE*4 carriers (\%) & $790(29.3)$ & $733(28.2)$ & $156(26.8)$ \\
\hline
\end{tabular}


Table 2 Distribution of the CETP I405V polymorphism in cases and controls overall and by $\mathrm{APOE}^{*} 4$

\begin{tabular}{|c|c|c|c|c|c|c|}
\hline \multirow[t]{2}{*}{ Genotype } & \multicolumn{2}{|l|}{ Overall } & \multicolumn{2}{|l|}{$\mathrm{APOE}^{*} 4+$} & \multicolumn{2}{|l|}{ APOE*4- } \\
\hline & Cases (\%) & Controls (\%) & Cases (\%) & Controls (\%) & Cases $(\%)$ & Controls $(\%)$ \\
\hline$\overline{\text { II }}$ & $236(43.4)$ & $2604(46.1)$ & $106(49.8)$ & $684(46.7)$ & $121(38.8)$ & $1,806(45.9)$ \\
\hline IV & $249(45.8)$ & $2474(43.8)$ & $89(41.8)$ & 644 (43.9) & $151(48.4)$ & $1,738(44.1)$ \\
\hline VV & $59(10.8)$ & $566(10.0)$ & $18(8.5)$ & $138(9.4)$ & $* 40(12.8)$ & $394(10.0)$ \\
\hline Total & 544 & 5644 & 213 & 1466 & 312 & 3938 \\
\hline
\end{tabular}

$* p=0.04$

increased to $1.58(1.0-2.5, p=0.05)$. When we analyzed the incident and prevalent cases together we did not detect an effect of the VV genotype of the CETP gene on the risk of $\mathrm{AD}$ in those with APOE*4 $(p=0.65$; Table 3$)$. The difference in the relationship of the CETP gene and AD between $\mathrm{APOE}^{*} 4$ carriers and non-carriers was statistically significant ( $p$ for interaction $=0.04$ ). The mean age at onset in patients carrying the VV genotype of the CETP I405V polymorphism (88.64 years, $\mathrm{SD}=7.19)$ did not differ significantly compared to that of the II and IV carriers (88.75 years, $\mathrm{SD}=8.02$ for IV carriers and 87.75 years, $\mathrm{SD}=817$ for II carriers, $p=0.41$ ). In those without the APOE*4 allele, the difference in age at onset between VV carriers and non-carriers was also not significant $(p=0.48)$.

\section{Discussion}

Our results suggest an increased risk of AD for carriers of the VV genotype of the I405V polymorphism in the CETP gene. The increase in risk was 1.67-fold in non-carriers of the APOE*4 allele. No association was observed between this CETP polymorphism and $\mathrm{AD}$ in those with the APOE*4 allele. We detected a statistically significant difference in the relationship between CETP and AD in APOE* 4 carriers and non-carriers ( $p$ for interaction=0.04). The association was independent of serum HDL levels, which by itself was not associated with AD.

The relationship between lipid transfer proteins, such as CETP, and AD has been previously studied. In an experimental study, Yamada et al. [28] showed that in brains of patients with $\mathrm{AD}$, reactive astrocytes in gray and white matter exhibit CETP-like immunoreactivity. Thus, CETP-positive astrocytes may play a role in the pathology of Alzheimer's disease, in particular tissue repair. Our findings partly overlap with those of other genetic studies. The CETP C-629A and TaqI B polymorphisms have been studied with respect to AD. A study in a Spanish population of the relationship between the CETP C-629A and I405V polymorphisms and the $\mathrm{APOE}^{*} 4$ allele indicated that the CETP gene modifies AD risk possibly through modulation of brain cholesterol metabolism [17]. This modification effect was seen only for the C-629A polymorphism and not for the I405V. This could be explained by the LD pattern of

${ }^{a}$ Incident and prevalent cases included

${ }^{\mathrm{b}}$ Models adjusted for age, sex, and APOE*4

${ }^{\mathrm{c}}$ Model adjusted for age and sex

$1.33(0.96-1.90)$ $0.91(0.51-1.60)$ $1.67(1.11-2.52)$ OR VV $(95 \%$ CI $)$

$1.11(0.91-1.36)$

$0.91(0.66-1.26)$

\begin{tabular}{lll}
\hline & OR IV $(95 \% \mathrm{CI})$ & OR VV $(95 \% \mathrm{CI})$ \\
\hline Overall $^{\mathrm{b}}$ & $1.11(0.91-1.36)$ & $1.33(0.96-1.90)$ \\
APOE*4+ $^{\mathrm{c}}$ & $0.91(0.66-1.26)$ & $0.91(0.51-1.60)$ \\
APOE*4- $^{\mathrm{c}}$ & $1.26(0.96-1.64)$ & $1.67(1.11-2.52)$ \\
\hline
\end{tabular}
and $\mathrm{AD}^{\mathrm{a}}$ in the Rotterdam study 
these two polymorphisms, but according to data available in HapMap [29], the $D^{\prime}$ and $r^{2}$ values between these two variants are not high enough that can serve as tagging markers for each other in this gene $\left(D^{\prime}=0.51, r^{2}=0.076\right)$. On the other hand, studies that evaluated the effect of other promoter polymorphisms and the TaqI B polymorphism found no effect of this gene on the disease $[18,30]$.

Since the VV genotype is associated with lower levels of CETP and higher HDL, our study is compatible with the view that low CETP levels may increase the risk of AD through a reduction in neuronal repair capacity. An alternative mechanism is related to cholesterol removal by HDL; this is one of the mechanisms that cells use to keep the levels of cholesterol in their membranes fairly constant $[9,13,31]$. This would imply that VV carriers might be at lower risk of developing $\mathrm{AD}$. The fact that we found this group to be at a higher risk of $\mathrm{AD}$ could be explained by previous findings suggesting that the actions of HDL in the transfer of lipids in brain may differ from those in the peripheral system [32]. In fact, the processing of cholesterol in brain is restricted in the central nervous system by the blood-brain barrier, which is impermeable to plasma lipoproteins [33]. Unlike fatty acids that must be transported to the central nervous system from the periphery, brain cholesterol is mainly independent of dietary uptake or synthesis in the liver and is synthesized almost entirely in the brain [34]. The CETP and APOE genes overlap physiologically $[35,36]$, which provides extra support for a role of the CETP gene independent of the APOE gene in the risk of Alzheimer's disease. In our overall analysis (all cases and controls, all APOE*4 carriers), we observed a borderline significant association between the VV carriers and $\mathrm{AD}$ of 1.33 , (95\% CI 0.96-1.90 $p=0.08)$, which could indicate that the effect of the CETP gene is observable in both $\mathrm{APOE}^{*} 4$ groups, but after stratification by $\mathrm{APOE}^{*} 4$, in the carrier group, the effect of the CETP gene is overwhelmed by APOE.

Taken together, our results suggest that the $\mathrm{V}$ allele of the I405V polymorphism of the CETP gene increases the risk of AD independently of the APOE gene, probably through the regulation of cholesterol metabolism in the brain. Our data, however, are not supported by the literature, which calls for more studies needed to clarify the role of the CETP gene, as well as the CETP protein and HDL cholesterol, in AD.

Acknowledgement A. Arias-Vasquez is supported by a grant from the Centre of Medical Systems Biology, grant no. 297-2003 and the Hersenstichting Nederland. The Rotterdam study is supported by the Erasmus Medical Center and Erasmus University Rotterdam, the Netherlands Organization for Scientific Research (NWO), the Netherlands Organization for Health Research and Development (ZonMw), the Research Institute for Diseases in the Elderly (RIDE), the Ministry of Education, Culture and Science, the Ministry of Health, Welfare and Sports, the European Commission (DG XII), and the Municipality of Rotterdam.
The contributions of the general practitioners and pharmacists of the Ommoord district are greatly acknowledged. The authors declare no conflict of interest.

\section{References}

1. Mahley RW, Weisgraber KH, Huang Y (2006) Apolipoprotein E4: a causative factor and therapeutic target in neuropathology, including Alzheimer's disease. Proc Natl Acad Sci USA 103 (15):5644-5651

2. Yanagisawa K, Matsuzaki K (2002) Cholesterol-dependent aggregation of amyloid beta-protein. Ann N Y Acad Sci 977:384386

3. Yanagisawa K (2002) Cholesterol and pathological processes in Alzheimer's disease. J Neurosci Res 70(3):361-366

4. Puglielli L, Tanzi RE, Kovacs DM (2003) Alzheimer's disease: the cholesterol connection. Nat Neurosci 6(4):345-351

5. Michikawa M (2003) The role of cholesterol in pathogenesis of Alzheimer's disease: dual metabolic interaction between amyloid beta-protein and cholesterol. Mol Neurobiol 27(1):1-12

6. Michikawa M (2004) Neurodegenerative disorders and cholesterol. Curr Alzheimer Res 1(4):271-275

7. Abad-Rodriguez J, Ledesma MD, Craessaerts K, Perga S, Medina M, Delacourte A, Dingwall C, De Strooper B, Dotti CG (2004) Neuronal membrane cholesterol loss enhances amyloid peptide generation. J Cell Biol 167(5):953-960

8. Wolozin B, Kellman W, Ruosseau P, Celesia GG, Siegel G (2000) Decreased prevalence of Alzheimer disease associated with 3hydroxy-3-methyglutaryl coenzyme a reductase inhibitors. Arch Neurol 57(10):1439-1443

9. Simons M, Keller P, Dichgans J, Schulz JB (2001) Cholesterol and Alzheimer's disease: is there a link? Neurology 57(6):1089-1093

10. Mauch DH, Nagler K, Schumacher S, Goritz C, Muller EC, Otto A, Pfrieger FW (2001) Cns synaptogenesis promoted by gliaderived cholesterol. Science 294(5545):1354-1357

11. Fan QW, Yu W, Senda T, Yanagisawa K, Michikawa M (2001) Cholesterol-dependent modulation of tau phosphorylation in cultured neurons. J Neurochem 76(2):391-400

12. Reiss AB (2005) Cholesterol and apolipoprotein E in Alzheimer's disease. Am J Alzheimers Dis Other Dement 20(2):91-96

13. Hersberger M, von Eckardstein A (2005) Modulation of highdensity lipoprotein cholesterol metabolism and reverse cholesterol transport. Handb Exp Pharmacol (170):537-561

14. Barter PJ, Kastelein JJ (2006) Targeting cholesteryl ester transfer protein for the prevention and management of cardiovascular disease. J Am Coll Cardiol 47(3):492-499

15. Blankenberg S, Rupprecht HJ, Bickel C, Jiang XC, Poirier O, Lackner KJ, Meyer J, Cambien F, Tiret L (2003) Common genetic variation of the cholesteryl ester transfer protein gene strongly predicts future cardiovascular death in patients with coronary artery disease. J Am Coll Cardiol 41(11):1983-1989

16. Atzmon G, Rincon M, Rabizadeh P, Barzilai N (2005) Biological evidence for inheritance of exceptional longevity. Mech Ageing Dev 126(2):341-345

17. Rodriguez E, Mateo I, Infante J, Llorca J, Berciano J, Combarros O (2006) Cholesteryl Ester Transfer Protein (Cetp) polymorphism modifies the Alzheimer's disease risk associated with Apoe Epsilon4 Allele. J Neurol 253(2):181-185

18. Zhu H, Gopalraj RK, Kelly JF, Bennett DA, Estus S (2005) Lack of genetic association of cholesteryl ester transfer protein polymorphisms with late onset Alzheimer's disease. Neurosci Lett 381 $(1-2): 36-41$ 
19. Hofman A, Grobbee DE, de Jong PT, van den Ouweland FA (1991) Determinants of disease and disability in the elderly: the Rotterdam elderly study. Eur J Epidemiol 7(4):403-422

20. Vermeer SE, Prins ND, den Heijer T, Hofman A, Koudstaal PJ, Breteler MM (2003) Silent brain infarcts and the risk of dementia and cognitive decline. N Engl J Med 348(13):1215-1222

21. Barendregt JJ, Ott A (2005) Consistency of epidemiologic estimates. Eur J Epidemiol 20(10):827-832

22. Folstein MF, Folstein SE, McHugh PR (1975) "Mini-Mental State". A practical method for grading the cognitive state of patients for the clinician. J Psychiatr Res 12(3):189-198

23. Copeland JR, Kelleher MJ, Kellett JM, Gourlay AJ, Gurland BJ, Fleiss JL, Sharpe L (1976) A semi-structured clinical interview for the assessment of diagnosis and mental state in the elderly: the geriatric mental state schedule. I. Development and reliability. Psychol Med 6(3):439-449

24. American Psychiatry Association (1987) Diagnostic and statistical manual of mental disorders

25. McKhann G, Drachman D, Folstein M, Katzman R, Price D, Stadlan EM (1984) Clinical diagnosis of Alzheimer's disease: report of the NINCDS-ADRDA work group under the auspices of department of health and human services task force on Alzheimer's disease. Neurology 34(7):939-944

26. Miller SA, Dykes DD, Polesky HF (1988) A simple salting out procedure for extracting DNA from human nucleated cells. Nucleic Acids Res 16(3):1215

27. Wenham PR, Price WH, Blandell G (1991) Apolipoprotein E genotyping by one-stage Pcr. Lancet 337(8750):1158-1159
28. Yamada T, Kawata M, Arai H, Fukasawa M, Inoue K, Sato T (1995) Astroglial localization of cholesteryl ester transfer protein in normal and Alzheimer's disease brain tissues. Acta Neuropathol (Berl) 90(6):633-636

29. (2005) A Haplotype Map of the Human Genome. Nature 437 (7063):1299-1320

30. Fidani L, Goulas A, Crook R, Petersen RC, Tangalos E, Kotsis A, Hardy J (2004) An association study of the cholesteryl ester transfer protein taqi B polymorphism with late onset Alzheimer's disease. Neurosci Lett 357(2):152-154

31. Jiang XC, Zhou HW (2006) Plasma lipid transfer proteins. Curr Opin Lipidol 17(3):302-308

32. Bjorkhem I, Meaney S (2004) Brain cholesterol: long secret life behind a barrier. Arterioscler Thromb Vasc Biol 24 (5):806-815

33. Vance JE, Hayashi H, Karten B (2005) Cholesterol homeostasis in neurons and glial cells. Semin Cell Dev Biol 16(2):193-212

34. Jurevics H, Morell P (1995) Cholesterol for synthesis of myelin is made locally, not imported into brain. J Neurochem 64(2): 895-901

35. Carter CJ, Mahley RW, Huang Y, Weisgraber KH (2007) Convergence of genes implicated in Alzheimer's disease on the cerebral cholesterol shuttle: app, cholesterol, lipoproteins, and atherosclerosis putting cholesterol in its place: apoe and reverse cholesterol transport. Neurochem Int 50(1):12-38

36. Mahley RW, Huang Y, Weisgraber KH (2006) Putting cholesterol in its place: apoe and reverse cholesterol transport. J Clin Invest 116(5):1226-1229 